\title{
A importância do conhecimento nas escolas sobre o HPV: uma revisão narrativa
}

\author{
The importance of schoolchildren's knowledge about HPV: a literary review
}

La importancia del conocimiento de los escolares sobre el VPH: una revisión literaria

Klayton Bahiense Barros ${ }^{1 *}$, Ademilson Reis Corrêa1, Evan Pereira Barreto ${ }^{1}$, Daniele Alves Mesquita ${ }^{1}$, Valdete Leonidio Pereira ${ }^{1}$, Karla Liliane Lima de Souza ${ }^{1}$, Marcia Vania Lima de Souza ${ }^{1}$, Josinete Braga Borges Lordes ${ }^{1}$, Alanna Cris Silva Rodrigues ${ }^{2}$, Ronneo Lucio Silva Rodrigues ${ }^{1}$.

\section{RESUMO}

Objetivo: Apontar a importância do tratamento e a disseminação do conhecimento entre escolares sobre o papilomavírus humano (HPV). Revisão bibliográfica: O papilomavírus humano é a infecção sexualmente transmissível (DST) mais comum. Muitos pacientes com HPV não apresentam sintomas, mas ainda podem infectar outras pessoas por meio do contato sexual. Os sintomas podem incluir verrugas nos órgãos genitais ou na pele ao redor. A informação é a principal forma de prevenção, pois além de subsidiar meninos e meninas para que entendam como e como cuidar deles, também ajuda a acabar com os equívocos. Dados globais mostram que quase todas as pessoas estarão expostas ao HPV em algum momento de suas vidas, e os adolescentes são considerados o grupo mais vulnerável. A prevenção é a melhor forma de evitar a infecção pelo HPV, pois o exame de Papanicolau apenas auxilia na detecção precoce do câncer de colo uterino. Considerações finais: A escola é um canal ímpar para a transmissão de conhecimentos acerca do HPV, e um local apropriado para instruir os adolescentes de como devem se portar para evitar a contaminação e quais cuidados devem adotar para uma vida mais sadia e plena.

Palavras-chave: Promoção da saúde dos alunos, Infecções por papillomavirus, Educação sexual.

\begin{abstract}
Objective: To point out the importance of treatment and the dissemination of knowledge among students about human papillomavirus (HPV). Bibliographic review: Human papillomavirus is the most common sexually transmitted infection (STD). Many HPV patients have no symptoms, but can still infect others through sexual contact. Symptoms can include warts on Organs genitals or the surrounding skin. Information is the main form of prevention, because in addition to subsidizing boys and girls so that they understand how and how to take care of them, it also helps to end misunderstandings. Global data shows that almost everyone will be exposed to HPV at some point in their lives, and teenagers are considered to be the most vulnerable group. Prevention is the best way to avoid HPV infection, as the Pap test only helps in the early detection of cervical cancer. Final considerations: The school is a unique channel for the transmission of knowledge about HPV, and an appropriate place to instruct teenagers on how to behave to avoid contamination and what precautions to take for a healthier and fuller life.
\end{abstract}

Keywords: Student health promotion, Papillomavirus infections, Sex education.

${ }^{1}$ Faculdade Vale do Cricaré (FVC), São Mateus - ES. *E-mail: engklaytonbahiense@gmail.com.

${ }^{2}$ Faculdades Unidas do Norte de Minas (FUNORTE), Montes Claros - MG.

SUBMETIDO EM: $3 / 2021$

ACEITO EM: 3/2021

PUBLICADO EM: 4/2021 


\section{RESUMEN}

Objetivo: Señalar la importancia del tratamiento y la difusión del conocimiento entre los estudiantes sobre el virus del papiloma humano (VPH). Revisión bibliográfica: El virus del papiloma humano es la infección de transmisión sexual (ETS) más común. Muchos pacientes con VPH no presentan síntomas, pero aún pueden infectar a otros a través del contacto sexual. Los síntomas pueden incluir verrugas en los órganos genitales o la piel circundante. La información es la principal forma de prevención, ya que además de subsidiar a los niños y niñas para que entiendan cómo y cómo cuidarlos, también ayuda a acabar con los malentendidos. Los datos globales muestran que casi todas las personas estarán expuestas al VPH en algún momento de sus vidas, y se considera que los adolescentes son el grupo más vulnerable. La prevención es la mejor manera de evitar la infección por VPH, ya que la prueba de Papanicolaou solo ayuda en la detección temprana del cáncer de cuello uterino. Consideraciones finales: La escuela es un canal único para la transmisión de conocimientos sobre el VPH y un lugar apropiado para instruir a los adolescentes sobre cómo comportarse para evitar la contaminación y qué precauciones tomar para una vida más sana y plena.

Palabras clave: Promoción de la salud de los estudiantes, Infecciones por papilomavirus, Educación sexual.

\section{INTRODUÇÃO}

A infecção pelo papilomavírus humano (HPV) é uma doença sexualmente transmissível onipresente em todo o mundo, portanto, é muito importante o estudo do quadro epidemiológico com o objetivo de prevenção, diagnóstico e tratamento, pois está clinicamente relacionado à pele, verrugas venéreas, câncer cervical, verrugas genitais ou verrugas genitais planas. Basicamente, em comparação com outros tipos de HPV de baixo risco, os vírus HPV-16 e HPV-18 apresentam um risco maior de infecção porque foram integrados ao DNA do hospedeiro, mas os tipos 16 e 18 são os cânceres mais comuns no mundo, portanto, as vacinas são um método preventivo viável para pessoas que ainda não fizeram sexo (RODRIGUES AF e SOUSA JA, 2015).

A infecção pelo HPV é uma das doenças sexualmente transmissíveis (DST) mais comuns no mundo. Estima-se que pelo menos $75 \%$ a $80 \%$ da população será contaminada pelo HPV ao longo da vida. Mais de 630 milhões de homens e mulheres (1:10 pessoas) foram infectados. No Brasil, estima-se que 9 a 10 milhões de pessoas estejam infectadas com o vírus, ocorrendo 700 mil novos casos a cada ano. A infecção é causada principalmente por contato sexual desprotegido. No entanto, pode ocorrer por contato direto ou indireto com lesões em outras partes do corpo (ABREU MNS, et al., 2018).

A transmissão vertical ainda é descrita durante a gravidez ou durante o parto. As lesões aparecem na forma de verrugas comuns, verrugas genitais ou condiloma acuminado e são frequentemente chamadas de "crista de galo". O diagnóstico clínico é feito pela presença de lesões únicas ou múltiplas, granulares e nodulares. Na maioria dos casos, é assintomático e, quando presente, inclui coceira, hiperemia e descamação local (ABREU MNS, et al., 2018).

Ações educativas voltadas ao conhecimento e incentivo à vacinação devem ser pautadas no significado de vírus e câncer de colo uterino; vacinas contra HPV; rastreamento, diagnóstico e tratamento do câncer; prevenção de infecções sexualmente transmissíveis; participação e autonomia dos públicos-alvo, adotar comportamentos saudáveis. Essas atividades precisam ser realizadas na escola, pois é onde os jovens passam a maior parte do tempo. A comunicação deve ser clara, contínua, consistente e direcionada a diferentes grupos de pessoas, para aumentar a conscientização e promover esse tópico por meio de esportes, materiais educacionais, mídias sociais, telefones celulares e outras tecnologias modernas (SILVA PMC, et al., 2018).

A adolescência é caracterizada por intensas mudanças biológicas, sociais e psicológicas, nas quais os indivíduos vivenciam a transição da infância para a vida adulta e cada vez mais exploram seus desejos sexuais, o que os torna mais suscetíveis a agravos à saúde, principalmente às infecções sexualmente transmissíveis (IST). Nesse caso, considerando que os adolescentes passam a maior parte do tempo pesquisando nas escolas, é muito importante que as escolas divulguem informações relacionadas à 
conscientização dos adolescentes sobre os riscos, a fim de promover a disseminação do conhecimento sobre saúde sexual e reprodutiva, construção do conhecimento e socialização (PINHEIRO PLL e CADETE MMM, 2019).

Para tornar esses conhecimentos propícios à adoção de medidas de proteção à saúde dos jovens, ações educativas e reflexões que promovam mudanças de atitude são imprescindíveis, por se tratarem de um fator de alto risco para o HPV, uma das DST que afetam a população mundial, e suas características cancerígenas. É necessário que pais, profissionais de saúde e educadores orientem os adolescentes sobre comportamento sexual e HPV como estratégia para promover saúde e qualidade de vida e idealizar adultos saudáveis e incentivem métodos de prevenção como por exemplo a vacinação, que no Brasil já acontece nas escolas (PINHEIRO PLL e CADETE MMM, 2019).

A Organização Mundial da Saúde (OMS) recomenda o uso da vacina contra o HPV, principalmente para meninas de 9 a 14 anos, antes de se tornarem sexualmente ativas. As evidências sugerem que a vacinação de meninas reduz o risco de infecção por HPV em meninos. As vacinas são imunogênicas e eficazes na prevenção do câncer do colo do útero, que é causado principalmente pelos HPV 16 e 18. O esquema de vacinação recomendado é de duas doses com intervalo de seis meses entre a primeira e a segunda dose para pessoas de 9 a 14 anos. Uma pausa de não mais de 12-15 meses é sugerida para completar o esquema de vacinação antes da atividade sexual. Se o intervalo entre as doses for inferior a cinco meses, a terceira dose deve ser administrada pelo menos seis meses após a primeira dose (CARVALHO AMC, et al., 2019).

Objetiva-se nesta revisão apontar a importância do tratamento e a disseminação do conhecimento entre escolares sobre o papilomavírus humano (HPV).

\section{REVISÃO BIBLIOGRÁFICA}

A puberdade começa na adolescência e vai dos 8 aos 13 anos, podendo estender-se até os 21 . É a fase da vida em que o sujeito passa por mudanças biopsicossociais e busca suas emoções, identidade, independência e cuidadosamente traça seu projeto de carreira. Este é um período de mudanças nas habilidades intelectuais, interesses, atitudes e adaptações. É um período difícil para os jovens, assim como para pais e professores, porque é quando ocorrem as mudanças físicas, incluindo as sexuais. Hoje, a adolescência, embora universal, assume peculiaridades (SILVA AT, et al., 2015).

A atual geração de adolescentes, conhecida como Geração $Y$, millennium ou globalizada, cresceu e se desenvolveu em uma cibercultura onde as restrições de tempo e espaço, públicas e privadas, foram suspensas. Isso resultou em vínculos menos coerentes em geral, mas também permitiu uma geração globalizada e versátil, sem relação com modelos rígidos, com potencial criativo e oportunidades sem precedentes (SILVA AT, et al., 2015).

O conhecimento sobre o HPV é baixo em várias populações ao redor do mundo, especialmente no que diz respeito à sua associação com resultados alterados de citologia oncológica, câncer cervical e verrugas genitais. Existem poucas publicações avaliando o conhecimento da população brasileira sobre o HPV. Os estudos existentes foram realizados em pequenas amostras e mostraram que a maioria das mulheres e dos homens tem pouco conhecimento deste vírus. Outro aspecto amplamente discutido é a aceitabilidade das vacinas. Recomenda-se vacinar meninas e meninos de diferentes idades dependendo da legislação vigente em cada país. A vacinação antes da exposição ao HPV oferece proteção duradoura para mulheres e homens. No entanto, essa recomendação nem sempre é bem recebida e compreendida em vários países, tanto pelos pais quanto pelos pediatras (OSIS MJD, et al., 2014).

A faixa etária mais acometida pelo câncer do colo do útero é de 25 a 60 anos, porém, como o início da vida sexual facilita o acesso dos adolescentes aos problemas de saúde reprodutiva e sexual, os adolescentes constituem um grupo altamente vulnerável a essa situação. Nem sempre os adolescentes usam métodos anticoncepcionais durante a primeira relação sexual para protegê-los de uma gravidez indesejada e de DST/AIDS. Estudos mostraram que a infecção por HPV, o principal carcinógeno do câncer cervical, ocorre nos primeiros estágios da vida sexual do adolescente ou por volta dos 20 anos (CIRINO FMSB, et al., 2010). 
Prestar atenção ao comportamento sexual dos adolescentes pode ajudar a reduzir suas necessidades de problemas pessoais e sociais. Nesse caso, destaca-se o papel fundamental da escola na educação sexual, por ser não apenas um ambiente propício para o aprendizado da anatomia e fisiologia humana, mas também de métodos de prevenção da gravidez precoce e das infecções sexualmente transmissíveis. Levando em consideração que depois do ambiente familiar, a escola é um complemento à educação proporcionada pela família, que tem grande responsabilidade pela educação dos alunos. Durante a escola, o desenvolvimento físico dos hormônios começa a evidenciar o desejo sexual dos adolescentes. A escola é responsável por orientar por meio de discussões relacionadas ao tema, constituindo assim, compromisso dos educadores (ALMEIDA RAAS, et al., 2017).

Estudos em adolescentes mostram que eles têm ideias erradas sobre o HPV, por exemplo, que o HPV é uma doença que pode ser adquirida por meio de transfusões de sangue, compartilhamento de agulhas e seringas para injeção ou convivência com pacientes infectados. Outros equívocos também surgem, como a crença de que o HPV só pode ser transmitido de homens para mulheres e o mito de que o HPV é uma doença de mulheres promíscuas. Informar e conscientizar os adolescentes sobre o HPV e seus riscos e como evitálo pode reduzir a contaminação pelo vírus. Surge aí a necessidade de introduzir através da educação básica, conhecimentos corretos sobre a transmissibilidade do vírus, formas de se prevenir e como e quando buscar o aparato da saúde pública para realizar exames como o Papanicolau (PANOBIANCO MS, et al., 2013).

\section{A vacinação contra o HPV nas escolas}

Os adolescentes são um dos grupos prioritários do Programa Nacional de Imunizações (PNI) no Brasil pela alta susceptibilidade a certas doenças evitáveis pela vacinação e, principalmente, pela baixa cobertura vacinal dessa faixa etária. A adolescência tem mudanças e necessidades importantes. Esta fase inclui 0 momento de escolha e decisão, e às vezes penetra nos aspectos negativos, como o aumento da exposição a fatores de risco causados pelas condições sociais dos adolescentes. O conceito de risco adolescente pode estar relacionado à exposição à violência, drogas e experiências sexuais prematuras. Dito isso, o Ministério da Saúde recomenda que os jovens recebam a vacina contra hepatite B (três doses), vacina contra difteria e tétano (uma dose a cada 10 anos), febre amarela (duas doses) e triplo vírus (duas doses). Para o HPV em meninas de 9 a 13 anos e HPV em meninos de 12 a 13 em 2017 (VIEGAS SMF, et al., 2019).

A vacinação de jovens é uma questão complexa. Nesta fase da vida, muitos jovens encontram-se invencíveis, gozam de boa saúde e mal vão ao consultório médico. Para o papilomavírus humano, meninas de 9 a 13 anos podem ser vacinadas por meio do Programa Nacional de Imunizações do Ministério da Saúde. Essa faixa etária é definida porque o vírus é transmitido por contato sexual, portanto, a proteção deve ser fornecida antes do início da vida adulta. As mulheres jovens que receberem a vacina não terão câncer cervical (BRASIL, 2016).

O HPV é responsável por 99\% dos casos de câncer cervical. No Brasil, são registrados mais de 16 mil casos de câncer a cada ano, o terceiro tipo de câncer que mais atinge as mulheres. Portanto, a relevância da prevenção por meio de vacinas pode prevenir a maioria dos tipos de vírus cancerígenos. Na verdade, para a imunização, é importante que as mulheres jovens recebam duas doses com intervalo mínimo de seis meses e máximo de 15 meses (BRASIL, 2016).

Devido à alta incidência, o HPV é considerado um problema de saúde pública e, por meio da vacinação, ações que visem prevenir a disseminação desse vírus são essenciais. Tendo em vista os benefícios da vacinação, alguns países estão gradualmente incorporando vacinas em seus planos de saúde. Até $2017,8 \%$ de aproximadamente 67 países já forneceram vacinas. No Brasil, a vacinação contra o HPV passou a fazer parte do calendário de vacinação do Sistema Único de Saúde (SUS) em 2014, exceto para determinadas populações especiais (por exemplo, pacientes com HIV/AIDS, pacientes com câncer e transplantes de órgãos sólidos e medula óssea). A vacinação no Brasil acontece também nas escolas através do programa saúde na escola, pois a faixa de 9 a 14 anos se tornou público alvo do programa de prevenção de doenças do Ministério da Saúde no Brasil (GENTIL DF e CORDEIRO MJJA, 2020).

Nas Américas, a vacina contra o HPV foi introduzida nos Estados Unidos em 2006 e, em meados de 2019, foi incluída no calendário em 40 países e regiões. A vacina mais comumente usada em 2020 é a vacina quadrivalente, que é recomendada para meninas e mulheres entre 9 e 45 anos e meninos e homens entre 9 
e 26 anos. Esta vacina pode prevenir os tipos de HPV 6, 11, 16 e 18. No Brasil, a vacina quadrivalente contra o HPV foi incluída no Programa Nacional de Imunizações (PNI) gratuitamente em 2014. A população-alvo é gradativamente incluída no plano de vacinação. O programa começou com meninas de 11 a 13 anos em 2014, expandiu-se para a faixa etária de 9 a 11 anos em 2015 e expandiu-se para meninas de 14 anos em 2017. Naquele ano, o programa foi direcionado a meninas entre 9 e 14 anos e meninos entre 11 e 14 anos (MOURA LL, et al., 2021).

A vacinação é um direito que deve ser respeitado, protegido e garantido. A Convenção sobre os Direitos da Criança de 1989 e os princípios de justiça social estipulam que todas as crianças devem ter igual acesso a vacinas eficazes. Portanto, a cobertura vacinal é considerada um importante indicador da saúde e da qualidade da assistência prestada pelos serviços, indicando se os direitos da criança e do adolescente estão protegidos ou não (WOLKERS PCB, et al., 2016).

Embora um progresso substancial tenha sido feito no aumento da cobertura global da vacinação infantil, diferentes indicadores podem mascarar lacunas óbvias entre os países e até mesmo dentro deles. A taxa de cobertura vacinal dos chamados "países em desenvolvimento" ainda é menor do que o esperado, e os governos dos países desenvolvidos ou em desenvolvimento devem formular diretrizes e acordos eficazes para garantir o planejamento, governança, recursos, recursos humanos e financeiros para garantir direitos de imunização (WOLKERS PCB, et al., 2016).

\section{A educação sexual como instrumento de combate ao HPV}

O início da abordagem formal da sexualidade nas escolas brasileiras ocorreu nas décadas de 1820 e 1830. A educação sexual infantil foi parte da iniciativa de Fernando Azevedo, que em 1922 reformou o sistema educacional com ênfase no interesse moral e higiênico na criação dos filhos. No entanto, foi somente no final da década de 1980 e início da década de 1990, no auge da epidemia de HIV / AIDS, que o tópico da sexualidade ganhou um lugar de destaque nas discussões educacionais, mas ficou confinado ao conceito de 'sexo seguro'. A partir daquele momento, o discurso sobre sexo nas escolas brasileiras foi finalmente colonizado pelas ideias de saúde e prevenção de doenças sexualmente transmissíveis e gravidez na adolescência, consideradas sinônimos de questões de saúde física e social (RUSSO K e ARREGUY ME, 2015).

Dentre as contribuições políticas sobre o tema, destacamos os documentos produzidos nas conferências realizadas no Cairo e em Pequim na década de 1990. Esses documentos tratam de temas como direitos humanos, liberdade sexual, saúde e educação. Ressalta-se a responsabilidade do Estado, ou seja, promover o acesso da população às informações relacionadas à saúde sexual e reprodutiva por meio de políticas públicas, e ter a responsabilidade de tomar ações, incluindo temas de planejamento familiar, métodos anticoncepcionais, aborto seguro (permitido nacionalmente), serviços de aconselhamento e obstetrícia. Essa mudança também afetou a educação de crianças e jovens. É reconhecido que o sexo sempre foi parte integrante da disciplina desde a infância, portanto, a escola é considerada um lugar privilegiado para políticas e programas que garantam os direitos reprodutivos e sexuais de seus alunos no campo da educação (FURLANETTO MF, et al., 2018).

O comportamento sexual mudou ao longo dos anos, passando do padrão tradicional - que privilegiava a sexualidade relacionada à reprodução - à liberação sexual. Sem relação com a atividade sexual relacionada à procriação, a questão da contracepção se destaca em primeiro lugar. No processo desse movimento, há um aumento no número de doenças sexualmente transmissíveis - doenças sexualmente transmissíveis - o que aumentaria o foco na profilaxia limitada relacionada à contracepção (COSTA LA e GOLDENBERG $P$, 2013).

Ainda de acordo com a pesquisa de Costa LA e Goldenberg P (2013), com o advento da síndrome da imunodeficiência adquirida, a proposta do uso do preservativo masculino associado à prática do "sexo seguro" está se espalhando. Nesse caso, considerando a particularidade da transmissão e das manifestações na vida, o reconhecimento da importância do papilomavírus humano e doenças relacionadas vem se tornando um novo desafio no campo da saúde pública. Sendo importante lembrar que os preservativos não eliminam completamente o risco de contrair o vírus. 
Observe que a saúde sexual e reprodutiva dos adolescentes enfrenta alguns obstáculos e desafios. Se observarmos os esforços feitos por funcionários e organizações governamentais para promover a saúde sexual e reprodutiva da população jovem, por outro lado, eles ainda enfrentam enormes desafios. Por exemplo, nesta população, especialmente entre aqueles com menos de 15 anos de idade que vivem em países da América Latina (incluindo o Brasil), a taxa de fecundidade se estabilizou e aumentou em alguns dos grupos mais vulneráveis. Também foi observado que a população jovem tem uma alta carga de doenças relacionadas à gravidez e parto não planejados, sem mencionar as infecções sexualmente transmissíveis, incluindo o vírus da imunodeficiência humana/síndrome da imunodeficiência e HPV (FELISBINO-MENDES MS, et al., 2018).

Destaca-se a baixa cobertura vacinal contra o papilomavírus humano (HPV) no Brasil, devido à adesão insuficiente de pais e adolescentes por motivos religiosos, associação entre HPV e atividade sexual e efeitos colaterais, incluindo desinformação, e sem evidências científicas. Além disso, muitos adolescentes não reconhecem o HPV como uma doença sexualmente transmissível. Sabe-se que a falta de informação sobre sua saúde e direitos, dificuldade de acesso a métodos anticoncepcionais, aspectos culturais e sociais, baixa escolaridade e baixa renda, violência e abuso sexual, bem como as desigualdades de gênero são fatores que contribuem para a persistência e crescimento desses problemas, entre os adolescentes. Outras causas foram investigadas em vários países e as evidências sugerem que a falta de educação sexual formal e estruturada por parte das escolas e dos pais está envolvida no processo (FELISBINO-MENDES MS, et al., 2018).

Prestar atenção ao comportamento sexual dos adolescentes pode ajudar a reduzir suas necessidades de problemas pessoais e sociais. Enfatizar o papel fundamental da escola na educação sexual, pois não é apenas uma forma de aprender a anatomia e fisiologia humana, prevenir a gravidez precoce e doenças venéreas, mas também um ambiente adequado para o seu desenvolvimento autônomo. No entanto, esse papel também pertence a outros departamentos, como a secretaria de saúde, e seus profissionais devem orientar pais e filhos sobre essa questão, o que requer a compreensão da formação cultural, pois a cultura é um dos fatores decisivos para os agravos à saúde e no processo de educação em saúde (CARNEIRO RF, et al., 2015).

\section{CONSIDERAÇÕES FINAIS}

Sabendo que a vida escolar é um longo preparo para vida, e corrobora com as necessidades sociais em conjunto com outros setores do Estado, como por exemplo a saúde pública. A educação sexual não age como incentivadora de sexo, mas age de forma a prevenir a proliferação de DSTs entre adolescentes. E o conhecimento de escolares sobre o HPV além da vacinação nas escolas é um método muito eficaz para prevenir o câncer cervical, que é um dos cânceres que mais mata mulheres no Brasil e no Mundo.

\section{REFERÊNCIAS}

1. ABREU MNS, et al. Conhecimento e percepção sobre o HPV na população com mais de 18 anos da cidade de Ipatinga, MG, Brasil. Ciência \& Saúde Coletiva, 2018; 23(3):849-860.

2. ALMEIDA RAAS, et al. Conhecimento de adolescentes relacionados às doenças sexualmente transmissíveis e gravidez. Revista Brasileira de Enfermagem, 2017; 70(5): 1022-1039.

3. RUSSO K, ARREGUY ME. Projeto "Saúde e Prevenção nas Escolas": percepções de professores e alunos sobre a distribuição de preservativos masculinos no ambiente escolar. PhysisRevista de Saúde Coletiva, 2015; 25(2): 501523.

4. BRASIL. VACINAR contra o HPV na escola é uma estratégia de sucesso: Ministério da Saúde, Brasília. 2016. Disponível em: http://www.blog.saude.gov.br/index.php/entenda-o-sus/51186-vacinar-contra-o-hpv-na-escola-e-umaestrategia-de-sucesso. Acesso em: 27 de fev. 2021.

5. CARNEIRO RF, et al. Educação sexual na adolescência: uma abordagem no contexto escolar. Sanare, 2015; 14(1): 104-108.

6. CARVALHO AMC, et al. Adesão à vacina HPV entre os adolescentes: revisão integrativa. Texto \& Contexto Enfermagem, 2019; 28(2): 1-11.

7. CIRINO FMSB, et al. Conhecimento, atitude e práticas na prevenção do câncer de colo uterino e hpv em adolescentes. Escola Anna Nery, 2010; 14(1): 126-134.

8. COSTA LA, GOLDENBERG P. Papilomavírus humano (HPV) entre jovens: um sinal de alerta. Saúde e Sociedade, $2013 ; 22(1): 249-261$. 
9. FELISBINO-MENDES MS, et al. Análise dos indicadores de saúde sexual e reprodutiva de adolescentes brasileiros, 2009, 2012 e 2015. Ver. Bra. Epidemiol., 2018; 21(1): 1-14.

10. FURLANETTO MF, et al. Educação sexual em escolas brasileiras: revisão sistemática da literatura. Cadernos de Pesquisa, 2018; 48(168): 550-571.

11. GENTIL DF, CORDEIRO MJJA. Programa Saúde na Escola: a vacinação contra o HPV na percepção de gestores escolares. Interfaces da Educação, 2020; 11(31): 550-581.

12. MOURA LL, et al. Cobertura da vacina papilomavírus humano (HPV) no Brasil: heterogeneidade espacial e entre coortes etárias. Rev. Bras. Epidemiol, 2021; 24(1): 1-12.

13. OSIS MJD, et al. Conhecimento e atitude de usuários do SUS sobre o HPV e as vacinas disponíveis no Brasil. Rev Saúde Pública, 2014; 48(1): 123-133.

14. PANOBIANCO MS, et al. O conhecimento sobre o HPV entre adolescentes estudantes de graduação em enfermagem. Texto \& Contexto - Enfermagem, 2013; 22(1): 201-207.

15. PINHEIRO PLL, CADETE MMM. O conhecimento dos adolescentes escolarizados sobre o papiloma vírus humano: revisão integrativa. Enfermaría global, 2019; 56(1): 624-644.

16. RODRIGUES AF, SOUSA JÁ. Papilomavírus humano: prevenção e diagnóstico. R. Epidemiol. Control. Infec, 2015; 5(4): 197-202.

17. SILVA AT, et al. Conhecimento de adolescentes do ensino médio sobre DST/AIDS no sul do Brasil. Aletheia, 2015; 46(1): 34-49.

18. SILVA PMC, et al. Conhecimento e atitudes sobre o Papilomavírus humano e a vacinação. Escola Anna Nery, 2018; 22(2): 1-7.

19. VIEGAS SMF, et al. A vacinação e o saber do adolescente: educação em saúde e ações para a imunoprevenção. Ciência \& Saúde Coletiva, 2019; 24(2):351-360.

20. WOLKERS PCB, et al. O direito à imunização na infância e adolescência: uma revisão narrativa. Ciência y Enfermaria, 2016; 22(3): 85(96). 